Cochrane Database of Systematic Reviews

\title{
Pneumococcal vaccines for children and adults with bronchiectasis
} (Review)

Chang CC, Singleton RJ, Morris PS, Chang AB

Chang CC, Singleton RJ, Morris PS, Chang AB.

Pneumococcal vaccines for children and adults with bronchiectasis.

Cochrane Database of Systematic Reviews 2009, Issue 2. Art. No.: CD006316.

DOI: 10.1002/14651858.CD006316.pub3.

www.cochranelibrary.com 
TABLE OF CONTENTS

HEADER 1

ABSTRACT

PLAIN LANGUAGE SUMMARY

BACKGROUND

OBJECTIVES

METHODS

RESULTS

Figure 1.

Figure 2.

DISCUSSION

AUTHORS' CONCLUSIONS

ACKNOWLEDGEMENTS

REFERENCES

CHARACTERISTICS OF STUDIES

DATA AND ANALYSES

Analysis 1.1. Comparison 1 Adults, Outcome 1 Number of people with one or more acute respiratory exacerbation.

Analysis 1.2. Comparison 1 Adults, Outcome 2 Number of subjects with pneumonia. APPENDICES

WHAT'S NEW

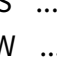

HISTORY

CONTRIBUTIONS OF AUTHORS

DECLARATIONS OF INTEREST

SOURCES OF SUPPORT

INDEX TERMS 
[Intervention Review]

\title{
Pneumococcal vaccines for children and adults with bronchiectasis
}

\author{
Christina C Chang ${ }^{1}$, Rosalyn J Singleton 2 , Peter S Morris ${ }^{3}$, Anne B Chang 3
}

1Department of Infectious Diseases, The Alfred Hospital, Monash University, Prahran, Australia. 2Arctic Investigations Program and Alaska Native Tribal Health Consortium, Centers for Disease Control and Prevention, National Center for Infectious Diseases,, Anchorage, Alaska, USA. ${ }^{3}$ Child Health Division, Menzies School of Health Research, Charles Darwin University, Darwin, Australia

Contact address: Christina C Chang, Department of Infectious Diseases, The Alfred Hospital, Monash University, Commercial Road, Prahran, Victoria, 3181, Australia. christina.chang@monash.edu, christina.chang@med.monash.edu.au ccchang339@hotmail.com.

Editorial group: Cochrane Airways Group.

Publication status and date: Edited (no change to conclusions), published in Issue 8, 2017.

Citation: Chang CC, Singleton RJ, Morris PS, Chang AB. Pneumococcal vaccines for children and adults with bronchiectasis. Cochrane Database of Systematic Reviews 2009, Issue 2. Art. No.: CD006316. DOI: 10.1002/14651858.CD006316.pub3.

Copyright (c 2017 The Cochrane Collaboration. Published by John Wiley \& Sons, Ltd.

\section{A B S T R A C T}

\section{Background}

Bronchiectasis is increasingly recognized as a major cause of respiratory morbidity especially in developing countries. Even in affluent countries, bronchiectasis is increasingly seen in some community subsections (e.g. Aboriginal communities) and occurs as a comorbidity and disease modifier in respiratory diseases such as chronic obstructive pulmonary disease (COPD). Respiratory exacerbations in people with bronchiectasis are associated with reduced quality of life, accelerated pulmonary decline, hospitalisation and even death. Conjugate pneumococcal vaccine is part of the routine infant immunisation schedule in many countries. Current recommendations for additional pneumococcal vaccination include children and adults with chronic suppurative disease.

\section{Objectives}

To evaluate the effectiveness of pneumococcal vaccine as routine management in children and adults with bronchiectasis in (a) reducing the severity and frequency of respiratory exacerbations and (b) pulmonary decline.

\section{Search methods}

The Cochrane Register of Controlled Trials (CENTRAL), the Cochrane Airways Group Specialised Register, MEDLINE and EMBASE databases were searched by the Cochrane Airways Group. Pharmaceutical manufacturers of pneumococcal vaccines were also contacted. The latest searches were performed in November 2008.

\section{Selection criteria}

All randomised controlled trials that utilised pneumococcal vaccine on children and adults with bronchiectasis. All types of pneumococcal vaccines were included.

\section{Data collection and analysis}

Results of searches were reviewed against pre-determined criteria for inclusion. No eligible trials were identified and thus no data was available for analysis. One small non-randomised controlled trial in children was reported.

\section{Main results}

One randomised controlled open label study in 167 adults with chronic lung disease (bronchiectasis and other diseases associated with bronchiectasis) compared 23-valent pneumococcal (PV) and influenza vaccine with influenza vaccine alone (control group). The study found a significant reduction in acute infective respiratory exacerbations in the $\mathrm{PV}$ group compared to the control group, $\mathrm{OR}=0.48$ ( $95 \% \mathrm{Cl}$ $0.26,0.88)$; number needed to treat to benefit $=6(95 \% \mathrm{Cl} 4,32)$ over 2-years. There was however no difference in episodes of pneumonia 
between groups and no data on pulmonary decline was available. In another study, a benefit in elimination of Strep. pneumoniae in the sputum was found in a non-randomised trial in children but no clinical effect was described.

\section{Authors' conclusions}

Current but limited evidence support the use of 23-valent pneumococcal vaccine as routine management in adults with bronchiectasis. Circumstantial evidence also support the use of routine 23-valent pneumococcal vaccination in children with bronchiectasis. Further randomised controlled trials examining the efficacy of this intervention using various vaccine types in different age groups are needed. There is no data on the efficacy of pneumococcal vaccine on pulmonary decline. With the lack of evidence in how often the vaccine should be given, it is recommended that health providers adhere to national guidelines.

\section{PLAIN LANGUAGE SUMMARY}

\section{Pneumonia (pneumococcal) vaccines for children and adults with bronchiectasis}

In many countries pneumonia vaccination (for the protection against infection of the bacteria pneumococcus), is part of the immunisation schedule for infants as well as for people with bronchiectasis. In this review, our search for randomised control trials that examined the effectiveness of pneumococcal vaccines for people with bronchiectasis revealed one randomised and one quasi-controlled trial. We conclude that, albeit the limitations of the review, adults and children (when age appropriate) with bronchiectasis should be vaccinated with the 23-valent polysaccharide pneumococcal vaccine as suggested in many national guidelines. Due to absence of data on how often the vaccine should be given, we recommend that national guidelines be followed until further evidence is available. 


\section{B A C K G R O U N D}

Bronchiectasis, sometimes termed an 'orphan's disease' (Callahan 2002 ) is increasingly recognized as a major cause of respiratory morbidity especially in developing countries (Karadag 2005) and in pockets of affluent countries (Chang 2003, Singleton 2000). Of diverse aetiology, bronchiectasis is often a result of repeated respiratory infections or may be due to rare immune deficiencies. Increasingly recognised as a common final pathway for a variety of diseases, it is seen to complicate both common and uncommon respiratory illnesses such as COPD, bronchiolitis obliterans, pan bronchiolitis (Poletti 2006), pneumoconiosis (Altin 2004), interstitial lung disease and sarcoidosis (Patel 2004, Chang 1998, Lewis 2002) and also secondary pulmonary illnesses such as autoimmune diseases and post tuberculosis (TB) (Buckles 1951). Its coexistence increases the morbidity and mortality of the underlying disease (Patel 2004, Lewis 2002, Keistinen 1997). For instance, bronchiectasis is reported to occur in $29-50 \%$ of COPD (Patel 2004, O'Brien 2000) and when present, increases the severity and frequency of respiratory exacerbations (Patel 2004, Gursel 2006). Thus, management of the symptoms and prevention of progression of bronchiectasis is important.

The dominant symptoms and signs of bronchiectasis are a productive or wet cough, dyspnoea on exertion and presence of other respiratory signs (clubbing, chest wall deformity, respiratory noises such as wheeze or crepitations on auscultation). In the long term, pulmonary decline may occur (Keistinen 1997, Twiss 2006). Children and adults with bronchiectasis suffer from recurrent acute exacerbations, some necessitating inpatient care. Effective management regimes for bronchiectasis should improve quality of life, reduce the frequency and severity of respiratory exacerbations and rate of pulmonary decline. Cole's 'vicious circle hypothesis' suggests microbial colonization or infection as a key factor in its pathophysiology as this often leads to bronchial obstruction and a normal or exaggerated inflammatory response (Cole 1986). Treatment modalities that prevent or limit respiratory infections should thus, prevent or reduce respiratory decline. Respiratory infection alone increases morbidity and reduces the quality of life in those with bronchiectasis (Martinez-Garcia 2005). Pneumococcal respiratory infections is a common respiratory pathogen in acute (Lucero 2004) and chronic respiratory diseases (Devitt 1977). Prevention of pneumococcal infections through the use of pneumococcal vaccine should in turn, be a useful routine management modality for children and adults with bronchiectasis. Indeed 5-yearly pneumococcal vaccination is recommended for patients with bronchiectasis (Chang 2002).

Pneumococcal vaccines are available in two major types; the older pneumococcal polysaccharide vaccine and the more recent pneumococcal conjugate vaccine. The 23-valent polysaccharide vaccine (PPV23) contains polysaccharide antigen from 23 serotypes and vaccine efficacy against invasive disease is estimated at 38-53\% (Conaty 2004). Although clinical trials in younger adults have generally shown efficacy against pneumococcal pneumonia and, or bacteraemia, the trial evidence in the elderly is less robust (Honkanen 1999). Effectiveness in case-control studies generally range from $56-81 \%$ except Forrester et al who demonstrated no effectiveness (Forrester 1987). The PPV23 vaccine is relatively ineffective in young children aged under 2 years (Lee 2003). The heptavalent pneumococcal conjugated vaccine (PCV7) is directed against seven serotypes and recommended for use in children less than 5 years of age (McEllistrem 2005). Universal childhood vaccination in the United States has resulted in $70 \%$ decrease in invasive pneumococcal disease (IPD) in children $<2$ years and indirectly, contributed to prevention of adult IPD (Lexau 2005). The possibility of replacement serotype disease mandates continued data surveillance (McEllistrem 2005). Vaccines also incur cost and can result in adverse reactions, mostly occurring as local pain and swelling (Walker 2005, Jackson 2006). A review on the efficacy of pneumococcal vaccines for bronchiectasis will help guide clinical practice.

Efficacy of pneumococcal vaccines for other chronic respiratory diseases (Sheikh 2002, Granger 2006) and otitis media (Straetemans 2004) are covered in other Cochrane reviews. This systematic review will evaluate the evidence of efficacy of pneumococcal vaccination in children and adults with bronchiectasis.

\section{O B JECTIVES}

To evaluate the effectiveness of pneumococcal vaccine as routine management in children and adults with bronchiectasis in (a) reducing the severity and frequency of respiratory exacerbations and (b) pulmonary decline.

\section{METHODS}

\section{Criteria for considering studies for this review}

\section{Types of studies}

All randomised controlled trials using pneumococcal vaccine in patients with bronchiectasis.

\section{Types of participants}

Adults or children with bronchiectasis (defined clinically or radiologically).

Exclusion criteria: Participants with other diseases where bronchiectasis is not present.

\section{Types of interventions}

All randomised controlled trials that utilised pneumococcal vaccine on children and adults with bronchiectasis. All types of pneumococcal vaccines were included.

\section{Types of outcome measures}

Attempts were made to obtain data on at least one of the following outcome measures:

(A) for short term effectiveness (12 months or less)

a) proportions of participants who had respiratory exacerbations

b) proportions of participants who were hospitalised,

c) total numbers of days with respiratory symptoms

d) total number of hospitalised days

e) mean difference in bronchiectasis severity control (QOL, cough diary, Likert scale, visual analogue scale, level of interference of cough, cough diary, etc),

f) proportions experiencing adverse effects of the intervention, (e.g. local reaction, exacerbation immediately post vaccination, systemic effects (myalgia, fever, fatigue), etc)

Outcomes (a) to (e) will be examined globally as well as also specifically to proven pneumococcal infections (from airway specimens or rising titres) 
(B) for medium to long term outcomes (more than 1 year)

g) radiology scores (high resolution computed tomography scans or chest radiograph)

h) lung function

I) bronchiectasis severity control (QOL, cough diary, Likert scale, visual analogue scale, level of interference of cough, cough diary, etc),

j) relevant airway markers of inflammation.

k) other non-respiratory outcomes (otitis media, bacteraemia, meningitis, etc) caused by pneumococcus.

\section{Search methods for identification of studies}

The following topic search strategy was used to identify relevant randomised controlled trials from electronic databases:

("bronchiectasis" OR "suppurative lung disease") AND ((vaccin* OR immunis $\left.{ }^{\star}\right)$ AND (pneum $\left.{ }^{\star}\right)$ ) (all as textword or index terms). For the full strategies see Appendix 1.

Trials were identified from the following sources:

1. The Cochrane Airways Group Specialised Trials Register

2. The Cochrane Central Register of Controlled Trials (CENTRAL)

3. MEDLINE (1966 to Nov 2008). Topic search strategy combined with the RCT search filter as outlined in the Airways Group module. 4. OLDMEDLINE (1950 to 1965). Topic search strategy combined with the RCT search filter as outlined in the Airways Group module. 5. EMBASE (1980 to Nov 2008).Topic search strategy combined with the RCT search filter as outlined in the Airways Group module.

6. The list of references in relevant publications.

7. Written communication with the authors of trials would have been included in the review if necessary.

7. Pharmaceutical companies that manufacture pneumococcal vaccines.

\section{Data collection and analysis}

Retrieval of studies: From the title, abstract, or descriptors, two reviewers (CC, AC) independently reviewed literature searches to identify potentially relevant trials for full review. Searches of bibliographies and texts were conducted to identify additional studies. From the full text using specific criteria, the same two reviewers independently selected trials for inclusion. Agreement would have been measured using kappa statistics. Disagreement would have been resolved by adjudication (RS and PM).

It was planned that trials that satisfied the inclusion criteria would have been reviewed and the following information recorded: study setting, year of study, source of funding, patient recruitment details (including number of eligible subjects), inclusion and exclusion criteria, other symptoms, randomisation and allocation concealment method, numbers of participants randomised, blinding (masking) of participants, care providers and outcome assessors, dose and type of intervention, duration of therapy, cointerventions, numbers of patients not followed up, reasons for withdrawals from study protocol (clinical, side-effects, refusal and other), details on side-effects of therapy, and whether intentionto-treat analyses were possible. Data would have been extracted on the outcomes described previously. Further information would have been requested from the authors when required.

The Revman 5 'risk of bias tool' as outlined in the Cochrane handbook (Higgins 2008) was utilised.

\section{STATISTICS}

Results from studies that met the inclusion criteria and reported any of the outcomes of interest were included in the meta-analyses when possible. For continuous variables, the summary weighted odds ratio and 95\% confidence interval (fixed effects model) would have been calculated (Cochrane statistical package, RevMan version 5). Studies using cross-over designs would be of limited value and it was planned that only the first arm of the cross-study (if any) would be utilised. Numbers needed to treat for benefit (NNTB) was calculated from the pooled OR and its $95 \% \mathrm{Cl}$ applied to a specified baseline risk using an online calculator (Cates 2003). If studies reported outcomes using different measurement scales, the standardised mean difference would have been estimated. Any heterogeneity between the study results would have been described and tested to see if it reached statistical significance using a chi-squared test. The $95 \%$ confidence interval estimated using a random effects model would have been included whenever there are concerns about statistical heterogeneity.

\section{SUB-GROUP ANALYSIS:}

The following a priori sub-group analyses was planned:

1. children (aged 18 years or less) and adults (>18 years)

2. types of pneumococcal vaccine

3. type of control group

4. participant type (bronchiectasis as primary disease vs bronchiectasis as co-existent disease)

5. severity of bronchiectasis (based on lung function)

Sensitivity analyses were also planned to assess the impact of the potentially important factors on the overall outcomes:

a) study quality;

b) variation in the inclusion criteria;

c) differences in the medications used in the intervention and comparison groups;

d) differences in outcome measures;

e) analysis using random effects model;

f) analysis by "treatment received"; and

g) analysis by "intention-to-treat".

\section{RES U LTS}

\section{Description of studies}

In the original search (2006) the Airways Group specialised register/ search identified 44 potentially relevant titles. After assessing the abstracts, 3 publications were considered for inclusion into review including one non-English article (Russian). Of the 3 potentially relevant publication but none fulfilled the study eligibility criteria (see Table of excluded studies). No additional studies were found in the review articles. No additional data were available from the two pharmaceutical companies contacted (Merck Sharp \& Dohme and Wyeth in Australia). The 2007 search revealed 5 abstracts of which none fulfilled the inclusion criteria. The 2008 search revealed 8 papers and one study (Furumoto 2008) was included.

The included study has been described in the Characteristics of included studies table. Some subjects had very severe lung disease (59 on home oxygen, 11 on home ventilation). The study was included as some subjects were clearly described as having bronchiectasis. The respiratory condition the other subjects had, has a large overlap with bronchiectasis especially when the disease is severe. Subjects were followed up for 2 years. There were no randomised controlled studies in children that assessed clinical 
outcomes. There was one quasi controlled study (Ryzhov 2005) that utilised a comparative group published in Russian (Ryzhov 2005). In this study (Ryzhov 2005) in children with chronic lung disease (including bronchiectasis), 25 were vaccinated with PPV23, 13 with Haemophilus influenzae vaccine and 40 children were not vaccinated. As there was otherwise little data, this study could not be included in the meta-analysis.

\section{Risk of bias in included studies}

Please see risk of bias table in included studies section. The sole randomised study (Furumoto 2008) included in this review has high risk of performance and detection bias.

\section{Effects of interventions}

\section{$\underline{\text { Adults }}$}

Figure 1. Forest plot of comparison: 1 Adults, outcome: 1.2 Number of people with acute respiratory exacerbation.

\begin{tabular}{|c|c|c|c|c|c|c|c|c|c|}
\hline Study or Subgroup & $\begin{array}{c}\text { Pneumococcal vac } \\
\text { Events }\end{array}$ & $\begin{array}{l}\text { cine } \\
\text { Total }\end{array}$ & $\begin{array}{c}\text { Contr } \\
\text { Events }\end{array}$ & $\begin{array}{l}\text { ol } \\
\text { Total }\end{array}$ & Weight & $\begin{array}{c}\text { Odds Ratio } \\
\text { M-H, Fixed, } 95 \% \mathrm{Cl}\end{array}$ & & $\begin{array}{c}\text { Odds Ratio } \\
\text { M-H, Fixed, } 95 \% \mathrm{Cl}\end{array}$ & \\
\hline \multicolumn{10}{|c|}{ 1.1.1 Any exacerbation } \\
\hline $\begin{array}{l}\text { Furumoto } 2008 \\
\text { Subtotal }(95 \% \mathrm{Cl})\end{array}$ & 41 & $\begin{array}{l}87 \\
87\end{array}$ & 50 & $\begin{array}{l}80 \\
80\end{array}$ & $\begin{array}{l}100.0 \% \\
\mathbf{1 0 0 . 0} \%\end{array}$ & $\begin{array}{r}0.53[0.29,0.99] \\
\mathbf{0 . 5 3}[0.29, \mathbf{0 . 9 9}]\end{array}$ & & & \\
\hline $\begin{array}{l}\text { Total events } \\
\text { Heterogeneity: Not a } \\
\text { Test for overall effect }\end{array}$ & $\begin{array}{l}41 \\
Z=1.98(P=0.05)\end{array}$ & & 50 & & & & & & \\
\hline \multicolumn{10}{|c|}{ 1.1.2 Infective exacerbations } \\
\hline $\begin{array}{l}\text { Furumoto } 2008 \\
\text { Subtotal }(95 \% \mathrm{Cl})\end{array}$ & 32 & $\begin{array}{l}87 \\
87\end{array}$ & 44 & $\begin{array}{l}80 \\
80\end{array}$ & $\begin{array}{l}100.0 \% \\
\mathbf{1 0 0 . 0} \%\end{array}$ & $\begin{array}{r}0.48[0.26,0.88] \\
\mathbf{0 . 4 8}[0.26, \mathbf{0 . 8 8}]\end{array}$ & & & \\
\hline $\begin{array}{l}\text { Total events } \\
\text { Heterogeneity: Not a } \\
\text { Test for overall effect }\end{array}$ & $\begin{array}{l}32 \\
Z=2.35(P=0.02)\end{array}$ & & 44 & & & & & & \\
\hline \multicolumn{10}{|c|}{ 1.1.3 Non-infective exacerbations } \\
\hline $\begin{array}{l}\text { Furumoto } 2008 \\
\text { Subtotal }(95 \% \mathrm{Cl})\end{array}$ & 9 & $\begin{array}{l}87 \\
87\end{array}$ & 6 & $\begin{array}{l}80 \\
80\end{array}$ & $\begin{array}{l}100.0 \% \\
\mathbf{1 0 0 . 0} \%\end{array}$ & $\begin{array}{l}1.42[0.48,4.19] \\
\mathbf{1 . 4 2}[0.48,4.19]\end{array}$ & & & \\
\hline $\begin{array}{l}\text { Total events } \\
\text { Heterogeneity: Not a } \\
\text { Test for overall effect }\end{array}$ & $\begin{array}{l}9 \\
Z=0.64(P=0.52)\end{array}$ & & 6 & & & & & & \\
\hline & & & & & & & $\begin{array}{lc}0.01 & 0.1 \\
\text { Favours pneumo }\end{array}$ & $\begin{array}{lr}1 & 10 \\
\text { al vacc } & \text { Favours control }\end{array}$ & 100 \\
\hline
\end{tabular}

Effect on exacerbations ( Analysis 1.1):

For number of people having had any respiratory exacerbations, the PV23 group was significantly better (less subjects with exacerbations) then the control group, OR $0.53(95 \% \mathrm{Cl} 0.29,0.99)$ Figure 1, NNTB over 2-years was $7(95 \% \mathrm{Cl} 4,424)$. With further evaluation, the difference between groups was mainly related to infective exacerbations (i.e. respiratory symptoms with increase in blood white cell count or serum C-reactive protein, as described in Characteristics of included studies). Comparing the PV23 group to controls, the OR for infective exacerbations was OR $=0.48(95 \% \mathrm{Cl}$ $0.26,0.88)$; number needed to treat to benefit $=6(95 \% \mathrm{Cl} 4,32)$ over 2 -years, see Figure 2. That for non-infective exacerbations was non significant, OR $1.42(0.48,4.19)$. 
Figure 2. Cates plot for NNT (B) over 2-years in reduction of infective exacerbation comparing PV23 vaccination to control in adults with chronic lung disease

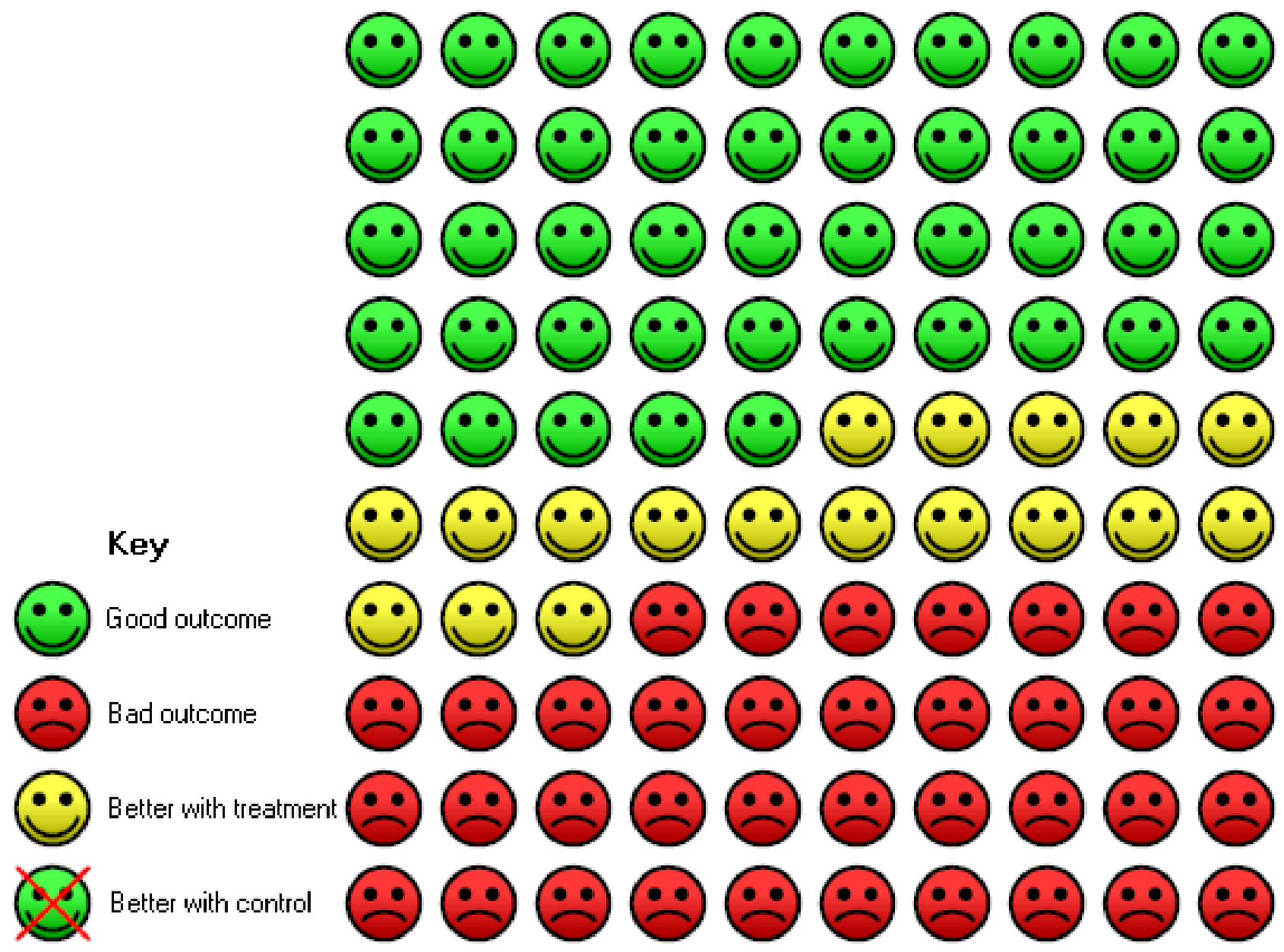

Effect on pneumonia ( Analysis 1.2): There was no difference between groups for the outcome of pneumonia

Other outcomes: Furumoto 2008 did not report on any pulmonary function. Seven subjects in each group ( $8.4 \%$ of the cohort studied) died during the follow up period of the study.

\section{Children}

There was only one study in children with bronchiectasis and this study utilised a comparative group, (i.e. a non-randomised study) published in Russian (Ryzhov 2005). In this study (Ryzhov 2005) in children with chronic lung disease (including bronchiectasis), 25 were vaccinated with PPV23, 13 with Haemophilus influenzae vaccine and 40 children were not vaccinated. The authors described that, a year after vaccination with PPV23, S. pneumoniae were isolated in monoculture in 3 out of 25 cases ( $88 \%$ elimination) (Ryzhov 2005).

It was not possible to perform any relevant sub-analysis.

\section{DISCUSSION}

In this review that evaluated the efficacy of pneumococcal vaccine in people with bronchiectasis for pulmonary outcomes, we found only one randomised controlled trial that was subject to bias as

it was an open-labelled trial. Nevertheless the study in 167 adults with chronic lung disease found that PV23 vaccination significantly reduced the number of people with respiratory exacerbation with NNTB of $7(95 \% \mathrm{Cl} 4,424)$ over 2 -years. The majority of this effect related to infective exacerbations, NNTB $6(95 \% \mathrm{Cl} 4,32)$ over 2-years. There was no difference between groups on number with pneumonia and no data for pulmonary decline was found. One controlled study that was not randomised (Ryzhov 2005) described efficacy with respect to microbiology of the sputum ( $88 \%$ elimination of $\mathrm{S}$ pneumoniae) but clinical evaluation was not examined in children.

Large trials and meta-analysis have demonstrated that pneumococcal vaccination protects children and adults from invasive pneumococcal disease (de Roux 2005), thus many recommendations exist for regular pneumococcal vaccination for those at risk (including patients with suppurative lung disease). This Cochrane review has significant limitations with the lack of studies. . Whilst we cannot always "wait for perfect data", others have cautioned against "availability creep" with respect to the gap between policy and evidence (Jefferson 2006). Until additional RCTs are undertaken to examine the question, we cannot be absolutely confident with the findings of this review that routine pneumococcal vaccination in children and adults with bronchiectasis is beneficial. The feasibility of

Pneumococcal vaccines for children and adults with bronchiectasis (Review)

Copyright $\odot 2017$ The Cochrane Collaboration. Published by John Wiley \& Sons, Ltd. 
performing RCTs in this target group is in question. For now, as children and adults with bronchiectasis are at increased risk for pneumonia and pneumococcal disease and there is some evidence that pneumococcal vaccine can reduce pneumonia and invasive pneumococcal disease (Lucero 2004), it would be prudent that providers follow guidelines from the national bodies such as Advisory Committee on Immunization Practices (in USA) (ACIP) and NIPS (Australia) (NIPS) regarding recommendations for pneumococcal vaccination of persons with bronchiectasis.

It is debatable whether the study (Furumoto 2008) we have included in this review fulfilled all the inclusion criteria, specifically that related to the diagnosis. We decided to include the study because a subgroup definitely had bronchiectasis and all the lung conditions in the subjects have a large overlap with bronchiectasis especially when the disease is severe. Although the study did not describe the severity of the chronic lung disease in all the subjects, it is likely that they were in the severe spectrum $(35.3 \%$ of cohort was on ambulatory oxygen and $6.6 \%$ was on home ventilation). Unless a HRCT scan is performed on each subject, it is very difficult to ascertain whether radiological bronchiectasis is present. The study was also limited with a risk of performance and detection bias. Nevertheless, in infective exacerbations where the greatest significance between groups was found, objective blood tests were utilised.

There was no data on how frequent pneumococcal vaccine should be given after the initial vaccination. Some advocate repeating PV23 after 5 years. In the absence of data on frequency of vaccination, we advocate that national guidelines be adhered to.

\section{AUTHORS' CONCLUSIONS}

\section{Implications for practice}

Limited evidence support the routine use of polysaccharide 23valent pneumococcal vaccine in adults with chronic lung disease including those with bronchiectasis. Other circumstantial data also suggests that pneumococcal vaccination is beneficial in children. There is no data on the efficacy of pneumococcal vaccine on pulmonary decline. There is also no data on how often the vaccination should be repeated. With the lack of evidence on this, it is recommended that health providers adhere to national guidelines. Individual risk factors for adverse events should be taken into account.

\section{Implications for research}

Randomised controlled trials to establish the efficacy of pneumococcal vaccination in reducing severity and frequency of respiratory exacerbations and pulmonary decline in people with bronchiectasis are needed. As vaccine response alters with age, age-based cohorts should include young children (less than 2 years), children, adults and older adults. Various vaccine types and microbiological surveillance for possible serotype replacement should also be examined in these RCTs. However the difficulty in performing a RCT in the target group is acknowledged.

\section{ACK N O WLEDGEMENTS}

We thank Toby Lasserson and Chris Cates from the Airways Group for their advice, supportive role and comments to the protocol and review. We are also grateful to Susan Hansen and Elizabeth Arnold for performing the relevant searches and obtaining the articles. We also thank Dr. Vasiliy Vlassov for translation of the Russian article. 


\section{RE F E R E N C E S}

\section{References to studies included in this review}

Furumoto 2008 \{published data only\}

Furumoto A, Ohkusa Y, Chen M, Kawakami K, Masaki H, Sueyasu $Y$, et al. Additive effect of pneumococcal vaccine and influenza vaccine on acute exacerbation in patients with chronic lung disease. Vaccine 2008;26(33):4284-9.

\section{References to studies excluded from this review}

Ryzhov 2005 \{published data only\}

Ryzhov AA, Katosova LK, Kostinov MP, Volkov IK, Magarshak 00. Evaluation of the influence of the bacterial vaccines Pneumo-23 and Act-HIB on the course of the chronic inflammatory process of the respiratory organs in children. Zhurnal Mikrobiologii, Epidemiologii i Immunobiologii 2005;30(3):84-7.

van Kessel 2005 \{published data only\}

van Kessel DA, van Velzen-Blad $\mathrm{H}$, van den Bosch JM, Rijkers GT. Impaired pneumococcal antibody response in bronchiectasis of unknown aetiology. European Respiratory Journal 2005;25(3):482-9.

\section{Vendrell 2005 \{published data only\}}

Vendrell M, De Gracia J, Rodrigo MJ, Cruz MJ, Alvarez A, Garcia M, et al. Antibody production deficiency with normal IgG levels in bronchiectasis of unknown etiology. Chest 2005;127(1):197-204.

\section{References to studies awaiting assessment}

o Grady 2015 \{published data only\}

O'Grady KA, Grimwood K, Cripps A, Mulholland EK, Morris P, Torzillo PJ, et al. Does a 10-valent pneumococcal-Haemophilus influenzae protein $\mathrm{D}$ conjugate vaccine prevent respiratory exacerbations in children with recurrent protracted bacterial bronchitis, chronic suppurative lung disease and bronchiectasis: protocol for a randomised controlled trial. Trials 2013;14(1):282.

\section{Additional references}

ACIP

ACIP. Advisory Committee on Immunization Practices. http:// www.cdc.gov/nip/menus/vaccines.htm (accessed Dec 2006).

\section{Altin 2004}

Altin R, Savranlar A, Kart L, Mahmutyazicioglu K, Ozdemir H, Akdag B, et al. Presence and HRCT quantification of bronchiectasis in coal workers. European Journal of Radiology 2004;52(2):157-63.

\section{Buckles 1951}

Buckles MG, Potts WL, Davidson HB, Neptune WB. Bronchography in pulmonary tuberculosis, with histopathologic correlation in 82 resections. American Review of Tuberculosis 1951;64(4):394-407.

\section{Callahan 2002}

Callahan CW, Redding GJ. Bronchiectasis in children: orphan disease or persistent problem?. Pediatric pulmonology 2002;33(6):492-496.

\section{Cates 2003}

Cates CJ, Jefferson TO, Bara Al, Rowe BH. Vaccines for preventing influenza in people with asthma (Cochrane Review). Cochrane Database of Systematic Reviews 2003, Issue 4. [Art. No.: CD000364. DOI: 10.1002/14651858.CD000364.pub2.]

\section{Chang 1998}

Chang AB, Masel JP, Masters B. Post-infectious bronchiolitis obliterans: clinical, radiological and pulmonary function sequelae. Pediatric Radiology 1998;28(1):23-29.

\section{Chang 2002}

Chang AB, Grimwood K, Mulholland EK, Torzillo PJ. Bronchiectasis in Indigenous children in remote Australian communities. Medical Journal of Australia 2002;177(4):200-4.

\section{Chang 2003}

Chang AB, Masel JP, Boyce NC, Wheaton G, Torzillo PJ. NonCF bronchiectasis-clinical and HRCT evaluation. Pediatric Pulmonology 2003;35:477-83.

\section{Cole 1986}

Cole PJ. Inflammation: a two edged sword. The model of bronchiectasis. European Journal Respiratory Disease 1986;147(Suppl):6-15.

\section{Conaty 2004}

Conaty S, Watson L, Dinnes J, Waugh N. The effectiveness of pneumococcal polysaccharide vaccines in adults: a systematic review of observational studies and comparison with results from randomised controlled trials. Vaccine 2004;22(23-24):3214-24.

\section{de Roux 2005}

de Roux A, Lode H. Pneumococcal vaccination. European Respiratory Journal 2005;26(6):982-3.

\section{Devitt 1977}

Devitt L, Riley I, Hansman D. Human infection caused by penicillin-insensitive pneumococci. Medical Journal of Australia 1977;1(16):586-8.

\section{Forrester 1987}

Forrester HL, Jahnigen DW, LaForce FM. Inefficacy of pneumococcal vaccine in a high-risk population. American Journal of Medicine 1987;83(3):425-30.

\section{Granger 2006}

Granger R, Walters J, Poole PJ, Lasserson TJ, Mangtani P, Cates $\mathrm{CJ}$, et al. Injectable vaccines for preventing pneumococcal infection in patients with chronic obstructive pulmonary disease (Cochrane Review). Cochrane Database of Systematic Reviews 2006, Issue 4. [Art. No.: CD001390. DOI: 10.1002/14651858.CD001390.pub2.] 


\section{Gursel 2006}

Gursel G. Does coexistence with bronchiectasis influence intensive care unit outcome in patients with chronic obstructive pulmonary disease?. Heart Lung 2006;35(1):58-65.

\section{Higgins 2008}

Higgins JPT, Green S (editors). Cochrane Handbook for Systematic Reviews of Interventions Version 5.0.1 [updated September 2008]. The Cochrane Collaboration. Available from www.cochrane-handbook.org, 2008.

\section{Honkanen 1999}

Honkanen PO, Keistinen T, Miettinen L, Herva E, Sankilampi U, Laara E, et al. Incremental effectiveness of pneumococcal vaccine on simultaneously administered influenza vaccine in preventing pneumonia and pneumococcal pneumonia among persons aged 65 years or older. Vaccine $1999 ; 17(20-21): 2493-500$

\section{Jackson 2006}

Jackson LA, Nelson JC, Whitney CG, Neuzil KM, Benson P, Malais $D$, et al. Assessment of the safety of a third dose of pneumococcal polysaccharide vaccine in the Vaccine Safety Datalink population. Vaccine 2006;24(2):151-6.

\section{Jefferson 2006}

Jefferson T. Influenza vaccination: policy versus evidence. BMJ 2006;333(7574):912-5.

\section{Karadag 2005}

Karadag B, Karakoc F, Ersu R, Kut A, Bakac S, Dagli E. Non-cysticfibrosis bronchiectasis in children: a persisting problem in developing countries. Respiration 2005;72(3):233-8.

\section{Keistinen 1997}

Keistinen T, Saynajakangas O, Tuuponen T, Kivela SL. Bronchiectasis: an orphan disease with a poorly-understood prognosis. European Respiratory Journal 1997;10(12):2784-7.

\section{Lee 2003}

Lee CJ, Lee LH, Frasch CE. Protective immunity of pneumococcal glycoconjugates. Critical Reviews in Microbiology 2003;29(4):333-49.

\section{Lewis 2002}

Lewis MM, Mortelliti MP, Yeager H, Jr, Tsou E. Clinical bronchiectasis complicating pulmonary sarcoidosis: case series of seven patients. Sarcoidosis, vasculitis, and diffuse lung diseases 2002;19(2):154-9.

\section{Lexau 2005}

Lexau CA, Lynfield R, Danila R, Pilishvili T, Facklam R, Farley MM, et al. Changing epidemiology of invasive pneumococcal disease among older adults in the era of pediatric pneumococcal conjugate vaccine. JAMA 2005;294(16):2043-51.

\section{Lucero 2004}

Lucero MG, Dulalia VE, Parreno RN, Lim-Quianzon DM, Nohynek $\mathrm{H}$, Makela $\mathrm{H}$, et al. Pneumococcal conjugate vaccines for preventing vaccine-type invasive pneumococcal disease and pneumonia with consolidation on $\mathrm{x}$-ray in children under two years of age (Cochrane Review). Cochrane Database of Systematic Reviews 2004, Issue 4. [Art. No.: CD004977. DOI: 10.1002/14651858.CD004977.]

\section{Martinez-Garcia 2005}

Martinez-Garcia MA, Perpina-Tordera M, Roman-Sanchez P, Soler-Cataluna JJ. Quality-of-life determinants in patients with clinically stable bronchiectasis. Chest 2005;128(2):739-45.

\section{McEllistrem 2005}

McEllistrem MC, Adams JM, Patel K, Mendelsohn AB, Kaplan SL, Bradley JS, et al. Acute otitis media due to penicillinnonsusceptible Streptococcus pneumoniae before and after the introduction of the pneumococcal conjugate vaccine. Clinical Infectious Diseases 2005;40(12):1738-44.

\section{NIPS}

National Immunisation Program. http:// www.immunise.health.gov.au/internet/immunise/ publishing.nsf/Content/nips accessed Dec 2006.

\section{O'Brien 2000}

O'Brien C, Guest PJ, Hill SL, Stockley RA. Physiological and radiological characterisation of patients diagnosed with chronic obstructive pulmonary disease in primary care. Thorax 2000;55(8):635-42.

\section{Patel 2004}

Patel IS, Vlahos I, Wilkinson TM, Lloyd-Owen SJ, Donaldson GC, Wilks $\mathrm{M}$, et al. Bronchiectasis, exacerbation indices, and inflammation in chronic obstructive pulmonary disease. American Journal of Respiratory \& Critical Care Medicine 2004;170(4):400-7.

\section{Poletti 2006}

Poletti V, Casoni G, Chilosi M, Zompatori M. Diffuse panbronchiolitis. European Respiratory Journal 2006;28(4):862-71.

\section{Sheikh 2002}

Sheikh A, Alves B, Dhami S. Pneumococcal vaccine for asthma (Cochrane Review). Cochrane Database of Systematic Reviews 2002, Issue 1. [DOI: 10.1002/14651858.CD002165]

\section{Singleton 2000}

Singleton RJ, Morris A, Redding G, Poll J, Holck P, Martinez P, et al. Bronchiectasis in Alaska Native children: causes and clinical courses. Pediatric Pulmonology 2000;29(3):182-7.

\section{Straetemans 2004}

Straetemans M, Sanders EAM, Veenhoven RH, Schilder AGM, Damoiseaux RAMJ, Zielhuis GA. Pneumococcal vaccines for preventing otitis media (Cochrane Review). Cochrane Database of Systematic Reviews 2004, Issue 1. [DOI: 10.1002/14651858.CD001480.pub2]

\section{Twiss 2006}

Twiss J, Stewart AW, Byrnes CA. Longitudinal pulmonary function of childhood bronchiectasis and comparison with cystic fibrosis. Thorax 2006;61(5):414-8. 


\section{Walker 2005}

Walker FJ, Singleton RJ, Bulkow LR, Strikas RA, Butler JC.

Reactions after 3 or more doses of pneumococcal

CHARACTERISTICS OF STUDIES

Characteristics of included studies [ordered by study ID]

Furumoto 2008

Methods Multicentre parallel RCT involving 13 hospitals in the district of Kyushu and Okinawa (Japan) between November 2001 and April 2002. Subjects were seen monthly and with exacerbations, they visited a study physician.

Participants

191 enrolled but 167 completed. All had chronic lung disease (COPD ( $n=55)$, bronchiectasis (20), sequelae of pulmonary tuberculosis (50), sarcoidosis (1), interstitial lung disease (9), diffuse pan bronchiolitis (5), pneumoconiosis (14), bronchial asthma (13)).

Inclusion criteria were patients with chronic lung disease who previously experienced acute exacerbations, were able to comply with a schedule of monthly clinical visits and were between 40 and 80 years of age. Exclusion criteria: Patients who were pregnant or had immunocompromised conditions (e.g. active malignant diseases, renal insufficiency in dialysis or HIV infection, hypogammaglobulinaemia, anatomical or functional asplenia and who had previously received 23-valent PV.

Mean age: pneumococcal vaccine (PV) with influenza vaccine (IV) group=67.8, SD 9.5 years; IV alone group=70.1 SD 7.4 years.

Gender: PV group=60 (69\%), IV group=46 (57.5\%)

Home 02 use: PV group=27 (31\%), IV group=32 (40\%)

Home non-invasive pressure ventilation: PV group=6 (6.9\%), IV group=5 (6.3\%)

Interventions

23-valent pneumococcal vaccine (PV) and influenza vaccine (IV) compared to influenza vaccine alone. PV + IV group were separately immunized with $0.5 \mathrm{ml}$ of PV and $0.5 \mathrm{ml}$ of IV on separate occasions in $1 \mathrm{month}$ intervals, the participants in the IV group were immunized with $0.5 \mathrm{ml}$ of IV alone

Outcomes

Acute respiratory exacerbation defined by presence of criteria: (1) increased dyspnoea, (2) increased sputum volume and (3) increased sputum purulence, and (4) absence of newly appeared infiltration on a chest radiograph. Acute exacerbation was diagnosed when two of the three respiratory symptoms existed or when one of these and one of additional symptoms, such as a fever without any other causes or increased cough was present.

Acute infective respiratory exacerbation: above plus when the laboratory examinations revealed an increase in white blood cell counts (WCC) or serum C-reactive protein (CRP), in addition to the clinical symptoms of acute exacerbation.

Acute non-infective respiratory exacerbation: clinical symptoms of acute exacerbation without increase in WCC or serum CRP.

Follow-up period was 2-years.

\section{Risk of bias}


Furumoto 2008 (Continued)

\begin{tabular}{lll}
$\begin{array}{l}\text { Random sequence genera- } \\
\text { tion (selection bias) }\end{array}$ & Unclear risk & Not described \\
\hline $\begin{array}{l}\text { Allocation concealment } \\
\text { (selection bias) }\end{array}$ & Low risk & Use of envelopes \\
\hline $\begin{array}{l}\text { Blinding (performance } \\
\text { bias and detection bias) } \\
\text { Pneumonia }\end{array}$ & High risk & Open label trial \\
\hline $\begin{array}{l}\text { Blinding (performance } \\
\text { bias and detection bias) } \\
\begin{array}{l}\text { Acute infective respiratory } \\
\text { exacerbation }\end{array}\end{array}$ & High risk & Open label trial \\
\hline
\end{tabular}

\begin{tabular}{lll}
\hline $\begin{array}{l}\text { Blinding (performance } \\
\text { bias and detection bias) } \\
\begin{array}{l}\text { Acute non-infective respi- } \\
\text { ratory exacerbation }\end{array}\end{array}$ & Low risk & Defined by objective blood results; thus presumed blinded outcome \\
\hline $\begin{array}{l}\text { Incomplete outcome data } \\
\text { (attrition bias) }\end{array}$ & Low risk & $\begin{array}{l}\text { Proportion of possible missing outcomes highly unlikely to have clinical rel- } \\
\text { evant impact on intervention effect estimate (low numbers of drop outs and } \\
\text { outcomes in both groups } 0.096 \text { episodes per person year) }\end{array}$ \\
\hline
\end{tabular}

\begin{tabular}{lll}
\hline $\begin{array}{l}\text { Incomplete outcome data } \\
\text { (attrition bias) }\end{array}$ & Unclear risk & $\begin{array}{l}\text { Numbers lost and withdrawn in both groups given (7 in active arm, } 17 \text { in con- } \\
\text { trol arm) }\end{array}$ \\
$\begin{array}{l}\text { Acute infective respiratory } \\
\text { exacerbation }\end{array}$ & \\
\hline $\begin{array}{l}\text { Incomplete outcome data } \\
\text { (attrition bias) }\end{array}$ & Unclear risk & $\begin{array}{l}\text { Numbers lost and withdrawn in both groups given (7 in active arm, } 17 \text { in con- } \\
\text { trol arm) } \\
\text { acute non-infective respi- }\end{array}$ \\
\hline
\end{tabular}

Characteristics of excluded studies [ordered by study ID]

\begin{tabular}{ll}
\hline Study & Reason for exclusion \\
\hline Ryzhov 2005 & $\begin{array}{l}\text { Non RCT. This study in Russian was a comparative study in } 40 \text { controls (unvaccinated) and 25 chil- } \\
\text { dren with chronic lung disease (including bronchiectasis) using Pneumovax 23. Hib vaccination } \\
\text { was examined in another group. }\end{array}$ \\
\hline van Kessel 2005 & $\begin{array}{l}\text { Non RCT. Study examined antibody response to polysaccharide pneumococcal vaccine in 26 pa- } \\
\text { tients with bronchiectasis of unknown aetiology. }\end{array}$ \\
\hline Vendrell 2005 & $\begin{array}{l}\text { Han RCT. Study examined antibody response to a pneumococcal unconjugate vaccine and an } \\
\text { tasis of unknown etiology . }\end{array}$ \\
\hline
\end{tabular}

\section{DATA AND ANALYSES}




\section{Comparison 1. Adults}

\begin{tabular}{lllll}
\hline Outcome or subgroup title & $\begin{array}{l}\text { No. of } \\
\text { studies }\end{array}$ & $\begin{array}{l}\text { No. of } \\
\text { partici- } \\
\text { pants }\end{array}$ & Statistical method & Effect size \\
\hline $\begin{array}{l}1 \text { Number of people with one or } \\
\text { more acute respiratory exacerba- } \\
\text { tion }\end{array}$ & 1 & & Odds Ratio (M-H, Fixed, 95\% Cl) & Subtotals only \\
\hline $\begin{array}{lllll}1.1 \text { Any exacerbation } \\
1.2 \text { Infective exacerbations }\end{array}$ & 1 & 167 & Odds Ratio (M-H, Fixed, 95\% Cl) & $0.53[0.29,0.99]$ \\
\hline 1.3 Non-infective exacerbations & 1 & 167 & Odds Ratio (M-H, Fixed, 95\% Cl) & $0.48[0.26,0.88]$ \\
\hline $\begin{array}{l}2 \text { Number of subjects with pneumo- } \\
\text { nia }\end{array}$ & 1 & 167 & Odds Ratio (M-H, Fixed, 95\% Cl) & $1.42[0.48,4.19]$ \\
\hline
\end{tabular}

Analysis 1.1. Comparison 1 Adults, Outcome 1 Number of people with one or more acute respiratory exacerbation.

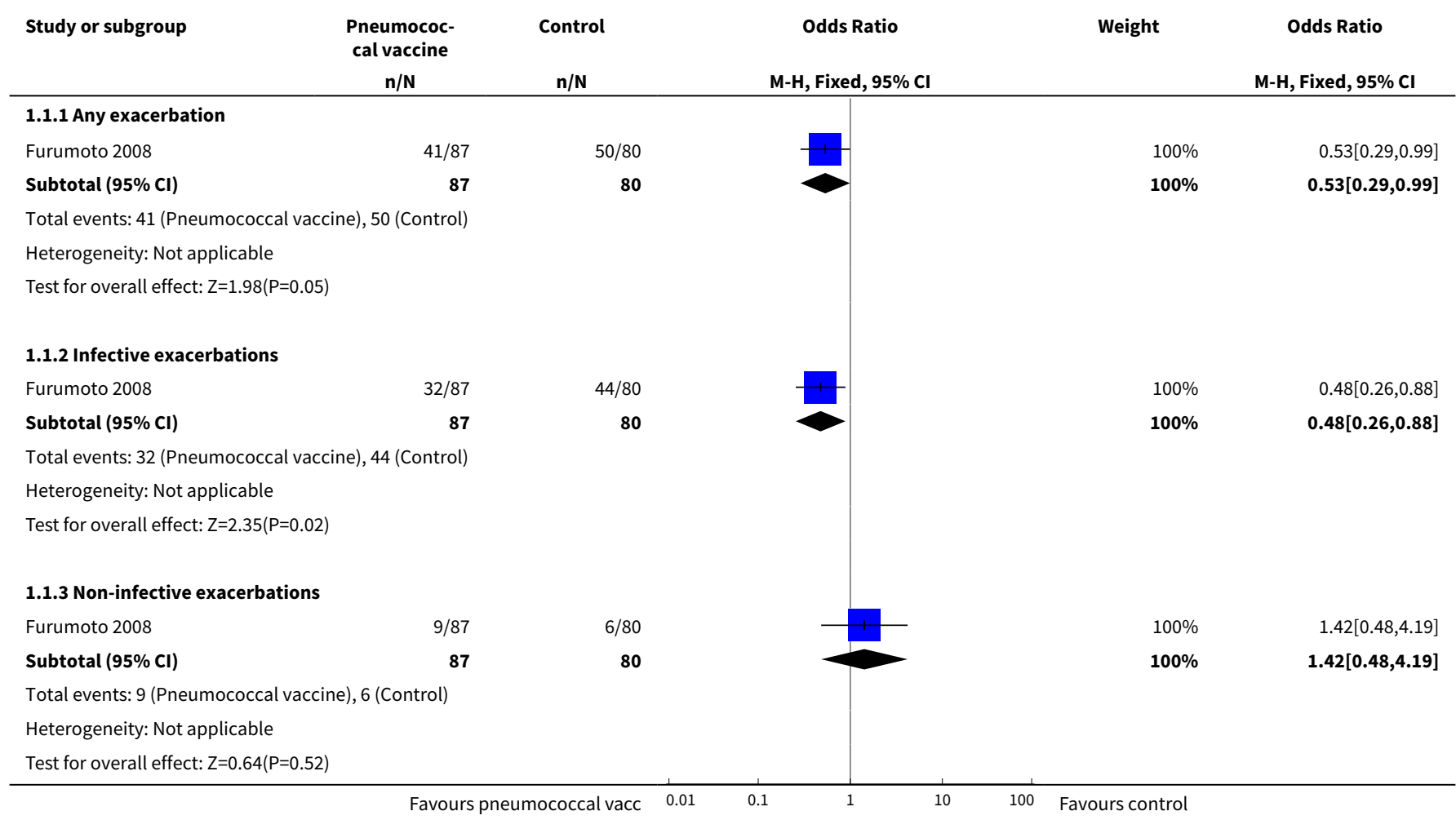


Analysis 1.2. Comparison 1 Adults, Outcome 2 Number of subjects with pneumonia.

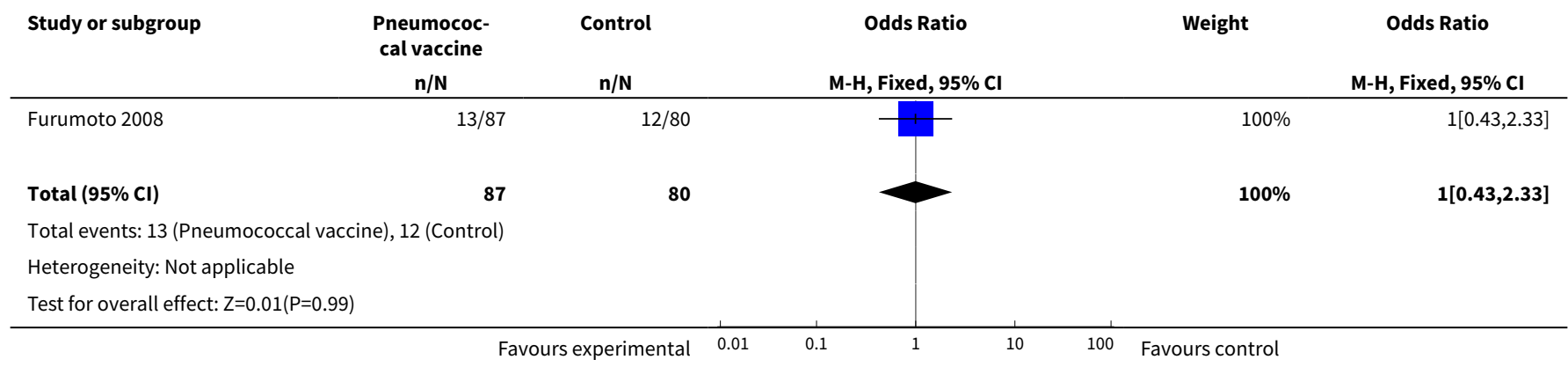

\section{APPENDICES}

\section{Appendix 1. Search strategies}

\begin{tabular}{|c|c|}
\hline Database & Search keywords \\
\hline AIRWAYS REGISTER & (bronchiectasis OR "suppurative lung disease") AND ((vaccin* OR immunis $\left.{ }^{\star}\right)$ AND (pneum)) \\
\hline CENTRAL & 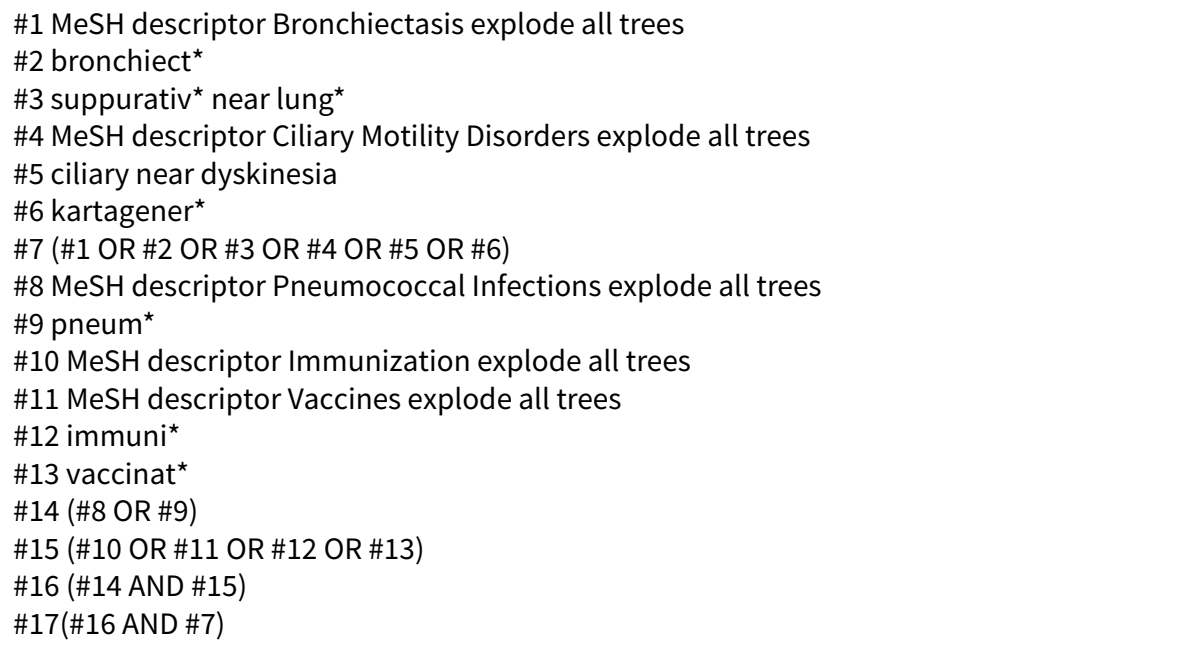 \\
\hline $\begin{array}{l}\text { MEDLINE and OLDMEDLINE } \\
\text { (Combined with RCT filter) }\end{array}$ & $\begin{array}{l}\text { 1. exp Bronchiectasis/ } \\
\text { 2. bronchiect\$.mp. } \\
\text { 3. (bronch\$ adj5 dilat\$).mp. } \\
\text { 4. (suppurativ\$ adj5 lung\$).mp. } \\
\text { 5. (ciliary adj3 dyskinesia).mp. } \\
\text { 6. kartagener\$.mp. } \\
\text { 7. or/1-6 } \\
\text { 8. exp Pneumococcal Infections/ } \\
\text { 9. pneum\$.mp. } \\
\text { 10. exp Immunization/ } \\
\text { 11. exp Vaccines/ } \\
\text { 12. vaccinat\$.mp. } \\
\text { 13. immuni\$.mp. } \\
\text { 14. (or/8-9) and (or/10-13) } \\
\text { 15. (pneumoc\$ adj5 vaccin\$).mp. } \\
\text { 16. (pneumoc\$ adj5 immuni\$).mp. }\end{array}$ \\
\hline
\end{tabular}


(Continued)
17. pneumococcal vaccines/
18. or/14-17
19. 18 and 7

\begin{tabular}{|c|c|}
\hline EMBASE & $\begin{array}{l}\text { 1. exp Bronchiectasis/ } \\
\text { 2. bronchiect\$.mp. }\end{array}$ \\
\hline (Combined with RCT filter) & $\begin{array}{l}\text { 3. (bronch\$ adj5 dilat\$).mp. } \\
\text { 4. (suppurativ\$ adj5 lung\$).mp. } \\
\text { 5. (ciliary adj3 dyskinesia).mp. } \\
\text { 6. kartagener\$.mp. } \\
\text { 7. or/1-6 } \\
\text { 8. exp Pneumococcal Infections/ } \\
\text { 9. pneum\$.mp. } \\
\text { 10. exp Immunization/ } \\
\text { 11. exp Vaccines/ } \\
\text { 12. vaccinat\$.mp. } \\
\text { 13. immuni\$.mp. } \\
\text { 14. (or/8-9) and (or/10-13) } \\
\text { 15. (pneumoc\$ adj5 vaccin\$).mp. } \\
\text { 16. (pneumoc } \$ \text { adj5 immuni\$).mp. } \\
\text { 17. pneumococcal vaccines/ } \\
\text { 18. or/14-17 } \\
\text { 19. } 18 \text { and } 7\end{array}$ \\
\hline
\end{tabular}

WHAT'S NEW

\begin{tabular}{lll}
\hline Date & Event & Description \\
\hline 5 July 2017 & Amended & $\begin{array}{l}\text { New literature search run to assess the need to update this re- } \\
\text { view. One potentially eligible study protocol identified and } \\
\text { added to Studies awaiting classification. }\end{array}$ \\
\hline
\end{tabular}

\section{H I S T O R Y}

Protocol first published: Issue 1, 2007

Review first published: Issue 2, 2007

\begin{tabular}{lll}
\hline Date & Event & Description \\
\hline 5 June 2014 & Amended & PLS title amended \\
\hline 12 March 2009 & Amended & Contact details changed \\
\hline 4 December 2008 & $\begin{array}{l}\text { New citation required and conclusions } \\
\text { have changed }\end{array}$ & Study on 167 people added to review \\
\hline 12 November 2008 & New search has been performed & Literature search re-run \\
\hline 16 April 2008 & Amended & Converted to new review format. \\
\hline 10 December 2006 & $\begin{array}{l}\text { New citation required and conclusions } \\
\text { have changed }\end{array}$ & Substantive amendment \\
\hline
\end{tabular}




\section{CONTRIBUTIONS OF AUTHORS}

For the protocol: Protocol was written by both CC and AC. RS reviewed the protocol. For the review: CC and AC selected articles from search, extracted data and wrote the review. RS and PM contributed to writing the review and would have been adjudicators if disagreements had occurred.

\section{DECLARATIONS OF INTEREST}

None declared.

\section{SOURCES OF SUPPORT}

\section{Internal sources}

- Royal Children's Hospital Foundation, Brisbane, Australia.

\section{External sources}

- National Health and Medical Research Council, Australia.

\section{N DEX TERMS}

\section{Medical Subject Headings (MeSH)}

Bronchiectasis [ ${ }^{*}$ complications]; Pneumococcal Infections [ ${ }^{*}$ prevention \& control]; Pneumococcal Vaccines [ ${ }^{*}$ therapeutic use]; Respiration Disorders [ ${ }^{*}$ prevention \& control]

\section{MeSH check words}

Adult; Child; Humans 